Revista de Educação e Pesquisa em Contabilidade Journal of Education and Research in Accounting Revista de Educación e Investigatión en Contabilidad
REPeC, Brasília, v. 6, n. 1, art. 5, p. 73-89, jan./mar. 2012

Disponível online em www.repec.org.br ISSN 1981-8610

\title{
Perfil Intraempreendedor e AÇões dos Gestores dos Cursos de CiênCIaS Contábeis da Região Oeste do Paraná
}

\author{
Silvana Anita Walter \\ Doutora em Administração pelo Programa de Pós-Graduação em Administração da Pontifícia Universidade Católica \\ do Paraná (PUCPR) \\ Endereço: Rua Paulo Zimmermann, $n^{\circ}$ 85, Edifício Bernhard, Apto. 302, Centro, Blumenau (SC) - CEP: 89.010-170 \\ E-mail: silvanaanita.walter@gmail.com
}

\section{Márcia Andréia Schneider}

Especialista em Lingua, Literatura e Ensino

Endereço: Rua Ulisses Siqueira de Lima, 150, Apto 202 Bloco B, Loteamento Ceniro Martins, São José/SC - CEP 88107-494

E-mail: marciadeia.schneider@gmail.com

\section{Daniela Torres da Rocha}

Mestre em Administração pela Pontifícia Universidade Católica do Paraná - PUCPR

Endereço: Rua Imaculada Conceição, $n^{\circ}$ 1155,Bloco Acadêmico, $1^{\circ}$ andar Sala 103 B, Prado Velho, Curitiba/PR CEP: 80215-901

E-mail: danitorres.rocha@gmail.com

\section{Maria José Carvalho de Souza Domingues}

Doutora em Engenharia da Produção pela Universidade Federal de Santa Catarina

Endereço: Rua Antônio da Veiga, $n^{\circ}$ 140, Victor Konder, Blumenau/SC CEP: 89010-971

E-mail:mjcsd2008@gmail.com

\section{Gérson Tontini}

Pós Doutor em Administração pela Califórnia State University

Professor da Universidade Regional de Blumenau - FURB

Endereço: Rua Antônio da Veiga, $n^{\circ}$ 140, Victor Konder, Blumenau/SC CEP: 89010-971

E-mail: gersontontini@gmail.com

\section{Resumo}

Este artigo objetiva identificar e analisar as ações, o perfil e as características intraempreendedoras dos gestores de cursos de graduação em Ciências Contábeis do oeste do Paraná. Assim, a questão de pesquisa formulada foi:

Editado em Português, Inglês e Espanhol. Versão original em Português.

Recebido em 10/12/10. Pedido de Revisão em 17/05/11. Resubmetido em 28/05/11. Aceito em 19/07/11 por Valcemiro Nossa (Editor). Publicado em 27/03/12. Organização responsável pelo periódico: CFC/FBC/ABRACICON.

Copyright (C 2012 REPEC. Todos os direitos, até mesmo de tradução, são reservados. É permitido citar parte de artigos sem autorização prévia, desde que seja identificada a fonte. 
Quais são as características intraempreendedoras e as principais ações dos gestores de cursos de Ciências Contábeis da região oeste do Paraná? Utilizou-se como método a pesquisa descritiva do tipo survey e, para coleta de dados, um questionário de Mastella (2005) e de Dornelas (2003), adaptado por Walter et al. (2007). Como principais resultados, constatou-se que os gestores são homens, tendo a maioria mais de 50 anos, titulação de especialista ou mestre e o principal vínculo com a instituição na qual atuam. Percebeu-se que as ações mais desenvolvidas pelos gestores apresentam-se voltadas às ações internas, fato que deveria ser objeto de reflexão, uma vez que ações consideradas mais importantes pelos gestores são menos realizadas. Assim, pouco tempo de dedicação à gestão, discrepâncias entre ações desejadas e efetivamente realizadas e demasiado enfoque interno de suas ações são aspectos a serem melhorados pelos gestores investigados. Todos os respondentes apresentam características intraempreendedoras. Percebe-se a necessidade de maior clareza no diálogo entre os superiores e os gestores para um maior alinhamento em relação ao desempenho atual dos gestores. Nota-se também que questões como a conciliação entre a carga horária ensino/gestão ainda precisa ser aperfeiçoada.

Palavras-chave: Gestores Universitários; Gestores de Curso; Coordenação de Curso; Perfil de Gestores; Ciências Contábeis.

\section{INTRODUÇÃO}

A universidade, enquanto organização complexa e atípica, tem passado por um processo de reestruturação e adaptação frente a diversos desafios, destacando-se a expansão do sistema de ensino superior, o aumento do controle externo via avaliações, as regulamentações em decorrência da Lei de Diretrizes e Bases (LDB), a utilização das tecnologias de informação e comunicação, bem como a necessidade de padrões gerenciais mais eficientes e eficazes.

Nas Instituições de Ensino Superior (IES), os desafios mencionados e as expectativas são respondidos pelos seus principais dirigentes ou, como são chamados atualmente, gestores. Desses gestores universitários, que são, em sua maioria, professores, é esperado um desempenho gerencial capaz de manter a instituição, sob sua gestão, competitiva frente às pressões ambientais internas e externas, conforme Grillo (1996), Marra e Melo (2003), Meyer Jr. (2000), Silva (2006) e Silva e Moraes (2003).

No contexto apresentado, ao ponderar sobre o reflexo do perfil e das características intraempreendedoras dos gestores relacionados à qualidade dos cursos, considerou-se importante visualizar esse perfil e as ações empreendidas pelos gestores das IES localizadas no estado do Paraná, Brasil. Essa relevância também se dá diante da preocupação da Coordenação de Aperfeiçoamento de Pessoal de Nível Superior (CAPES) e do governo brbasileiro com a adequação dos processos educacionais. Dessa forma, este artigo apresenta os resultados de uma pesquisa realizada em sete IES - sendo que uma dessas possui três campi e, portanto, três gestores- localizadas na região oeste do Paraná com o objetivo de identificar o perfil dos gestores dos cursos de Ciências Contábeis dessas IES, o exercício da função gerencial e analisar as características intraempreendedoras desses gestores, com base em um instrumento de coleta de dados de Mastella (2005) e de Dornelas (2003), adaptado por Walter et al. (2007). Assim, a questão de pesquisa formulada foi: Quais são as características intraempreendedoras e as principais ações dos gestores de cursos de Ciências Contábeis da região oeste do Paraná?

\section{GESTORES DE CURSO DAS INSTITUIÇÕES DE ENSINO SUPERIOR}

A atuação dos gestores do curso de Ciências Contábeis tem por base as atribuições formalmente definidas nos regimentos internos das IES. Dessa forma, o exercício da função é norteado por uma ação articuladora entre o corpo docente, discentes em formação e egressos visando assegurar o desenvolvimento de habilidades e competências previstas no Projeto Pedagógico do Curso, bem como o processo qualitativo da aprendizagem.

De acordo com Moraes (2004), três são os requisitos para exercer o cargo de gestor de curso nas IES brasileiras: ter titulação (mestre ou doutor) que atenda às exigências do Ministério da Edu- 
cação e Cultura (MEC), ser contratado pelo regime mensalista de 40 horas, o que proporciona maior dedicação ao curso, e ministrar aulas no curso que coordena.

Grillo (1996), Marra e Melo (2003), Meyer Jr. (2000), Silva (2006) e Silva e Moraes (2003) citam que, na maioria dos casos estudados, não há adequação entre a formação técnica do professor e as práticas gerenciais. Justifica-se essa afirmação pelo fato de que, na maioria dos casos, os gestores de curso adquirem habilidades gerenciais por meio de erros e acertos, ou seja, na prática.

O desempenho esperado do gestor, para Silva (2006), corresponde ao cumprimento das atribuições definidas pela instituição. Dessa forma, na gestão interna, torna-se questão importante a maneira de atingir resultados e as competências gerenciais enquanto capacidade de mobilização, de integração e de aplicação dos recursos de sua competência.

Grunow, Sabadin, Fassina e Domingues (2005) definem como atribuição básica dos gestores do curso de Ciências Contábeis - que possuem a função de coordenar -, planejar, juntamente com os demais docentes, todas as atividades do curso que visam ao desenvolvimento das seguintes competências: (1) coordenar as atividades de ensino, pesquisa e extensão do curso e organizar o currículo pleno do mesmo, ouvindo o corpo docente; (2) aprovar, no âmbito de sua competência, planos e programas de ensino e alterações curriculares, como também propor medidas para o aperfeiçoamento do ensino e condições para pesquisa e extensão; (3) supervisionar a integralização curricular, orientar alunos e deliberar sobre recursos ou representações de alunos a respeito de matéria didática e trabalhos escolares; (4) verificar a execução do sistema de avaliação dos corpos discente e docente e dar parecer na indicação e dispensa do docente; (5) convocar e presidir as reuniões do corpo docente do curso e coordenar os trabalhos dos membros deste; (6) acompanhar a assiduidade dos docentes e fiscalizar a observância do regime escolar e o cumprimento dos planos de ensino e dos demais planos de trabalho; (7) avaliar o desempenho docente segundo propostas dos colegiados superiores; (8) estabelecer, observadas as normas baixadas pelas IES, estudos e adaptações curriculares, bem como deliberar sobre pedidos de transferências e equivalências; (9) apresentar propostas para aquisição de material bibliográfico e outros equipamentos necessários para o bom desempenho do ensino, pesquisa e extensão do curso; (10) deliberar sobre a organização e administração de laboratórios e de outros materiais didáticos quando esses constituírem parte integrante do ensino e da pesquisa; (11) apresentar aos órgãos superiores da instituição relatórios das atividades do curso; (12) zelar pela regularidade e qualidade do ensino disponibilizado pelo curso e avaliar periodicamente o andamento e os resultados dos projetos de pesquisa e dos planos de extensão sob sua responsabilidade; e (13) cumprir e fazer cumprir as disposições do regimento geral e as deliberações dos órgãos colegiados, como também exercer outras atribuições que, pela sua natureza, recaiam sobre sua competência ou lhes sejam delegadas pelos demais órgãos.

Em síntese, cabe ao gestor do curso procurar exercer uma função de articulação entre corpos docente e discente para a consecução do processo de ensino-aprendizagem. Assim, a ele compete viabilizar ações de interação entre aluno, conhecimento e professor, tendo como instrumental de apoio as reuniões que priorizam as discussões pedagógicas e as reflexões coletivas.

Por meio do comportamento empreendedor dos seus gestores, as organizações percebem uma revitalização de inovação, de estratégias, de criatividade e de desenvolvimento administrativo (KURATKO et al., 1993).

Meyer Jr. (2000) aponta como características importantes do gestor: visão de futuro, domínio da tecnologia, visão estratégica, capacidade de decisão, prática de empowerment, gerenciamento de informações e o ato de empreender e participar. Nesse contexto, percebe-se a importância das características pessoais no que se refere ao comportamento dos gestores.

\section{INTRAEMPREENDEDORISMO}

Boulton, Carland e Hoy (1984) relatam, em seus estudos, pesquisadores que apontam características comuns aos empreendedores, estando entre eles: Mill (1848); Weber (1917); Schumpeter 
(1934); Sutton (1954); Hartmann (1959); McClelland (1961); Davids (1963); Pickle (1964); Palmer (1971), Hornaday e Aboud (1971); Winter (1973); Borland (1974); Liles (1974); Gasse (1977); Timmons (1978); Sexton (1980); Welsh e White (1981); Dunkelberg e Cooper (1982).

Contudo, as principais concepções sobre o empreendedor foram desenvolvidas teoricamente por Schumpeter em 1911, considerado, na literatura, como a pessoa que melhor analisou o empreendedor e sua inserção na economia (BARBIERI et al., 2003). Schumpeter (1982) assegura que o empreendedor desafia o mercado rompendo com o equilíbrio existente e aproveitando oportunidades para criar coisas novas e diferentes. Na década de 1960, os comportamentalistas, ao estudarem o empreendedor como pessoa, ampliaram o campo do empreendedorismo. Outra teoria de destaque na área é a de McClelland (1972) que, fundamentada na motivação psicológica, resultou em um dos poucos instrumentos de coleta de dados que mensura as características comportamentais dos empreendedores.

Timmons, Smollen e Dingee (1977) salientam que o empreendedorismo é uma revolução silenciosa que será, para o século XXI, mais do que a Revolução Industrial foi para o século XX. No Brasil, o movimento do empreendedorismo surgiu no início da década de 1980 nos cursos de administração de empresas. A primeira experiência foi a do professor Ronald Degen, em 1981, na Escola de Administração de Empresas da Fundação Getúlio Vargas em São Paulo. O professor Degen criou a disciplina Novos Negócios no curso de especialização em Administração. No entendimento de Degen (1989), o empreendedor é o responsável pela criação de novos produtos e mercados que apresentam vantagens, como maior eficiência e menor custo.

Com enfoque diferenciado do termo empreendedorismo - relacionado à criação de novas empresas (empreendedor start-up) -, o intraempreendedorismo ou empreendedorismo corporativo, foco deste estudo, relaciona-se, segundo Dornelas (2003), às ações empreendedoras desenvolvidas em uma organização já existente. Para Pinchot (1989) e Filion (1999), o que diferencia o intraempreendedor do empreendedor é que o primeiro atua de forma empreendedora inserido em uma organização já existente, enquanto o segundo atua criando novas organizações e negócios.

Pinchot (1989) definiu intrapreneur ou intraempreendedor como aquele que, mesmo sem deixar a organização em que atua, realiza atos de criação ou inovação típicos dos empreendedores. "Intraempreendedores são empregados que possuem iniciativas novas em organizações estabelecidas e fazem alguma diferença material. Eles propõem idéias novas e valiosas que eles são capazes de desenvolver, em um ambiente cultural favorável". (THOMPSON, 2004, p. 246). O termo intraempreendedor designa, portanto, o empreendedor corporativo, nomenclatura que também se aplica aos gestores de cursos de Ciências Contábeis.

Para muitos pesquisadores, os empreendedores corporativos possuem, praticamente, as mesmas características dos empreendedores start-up. Hornsby et al. (1993) afirmam que, apesar de muitas organizações não avaliarem as características de personalidade de seus empregados, é importante reconhecer sua influência no comportamento inovador. Os autores complementam que o comportamento intraempreendedor pode surgir por meio de treinamento ou de outras oportunidades intraempreendedoras. Para Walter et al. (2005), o intraempreendedor apresenta estilo mais proativo, visionário e flexível às mudanças. Esses pesquisadores identificaram em estudo teórico que necessidade de apoio e habilidade de ensinar os outros são duas características apenas dos intraempreendedores.

Segundo Pinchot (1989), os intraempreendedores são visionários; têm necessidade de agir; são dedicados; estabelecem metas autodeterminadas; estabelecem altos padrões internos; superam erros e fracassos; administram riscos; e possuem lealdade em seus negócios.

Kuratko, Montagno e Hornsby (1990) verificaram que os intraempreendedores são motivados, mas que também necessitam do apoio e do reconhecimento da organização para atuarem de forma empreendedora. Segundo Dornelas (2003), o intraempreendedor, ao identificar, desenvolver, capturar e programar novas oportunidades de negócio, requer que a organização faça mudanças na forma como os recursos são empregados criando, assim, novas competências empresariais e buscando, por meio dessas competências, novas possibilidades de posicionamento no mercado, bem como um com- 
promisso de longo prazo e criação de valor para os agentes internos e externos à organização, criatividade, motivação e superação.

Como a responsabilidade pelos resultados do desempenho pedagógico e administrativo dos cursos de graduação é, primeiramente, dos seus gestores, estes possuem uma função complexa e decisiva na qualidade desses cursos. Assim, este estudo traz uma reflexão sobre as características intraempreendedoras desses gestores, sob a ótica da autoavaliação e da avaliação das IES, enfocadas por Walter et al. (2005) em um estudo que adaptou dois questionários: o de Dornelas (2003), um dos poucos instrumentos que medem, sob a perspectiva da autoavaliação e da avaliação das IES, o perfil intraempreendedor, e o de Mastella (2005), de diagnóstico de gestão.

\section{MÉTODO DA PESQUISA}

Para alcançar os objetivos propostos neste estudo, utilizou-se como método a pesquisa de caráter descritivo do tipo levantamento ou survey que, de acordo com Gil (1999), descreve uma situação real e específica, ou seja, um determinado entrevistado, em situação e local específicos. Nesse caso, ainda segundo o mesmo autor, é possível analisar os dados por meio de comparações e testes estatísticos das diferenças encontradas entre os subgrupos, bem como podem ser realizadas análises estatísticas mais elaboradas.

A pesquisa descritiva, segundo Gil (1999), tem como objetivo principal descrever características de determinada população ou fenômeno ou estabelecer relações entre variáveis, sendo uma de suas características mais significativas a utilização de técnicas padronizadas de coleta de dados. Neste estudo, utilizaram-se, como instrumento de coleta de dados, dois questionários: o primeiro, baseado na pesquisa de Walter et al. (2007), foi respondido pelos gestores dos cursos de Ciências Contábeis das IES pesquisadas, e o segundo, modificado de Walter et al. (2007), foi respondido pelos superiores imediatos desses gestores (diretores gerais, diretores de centro, decanos, etc.).

O primeiro questionário para investigação do perfil dos gestores dividiu-se em três etapas distintas. Na primeira etapa, investigaram-se questões relativas ao perfil dos gestores, tendo como base o Diagnóstico de Gestão de Cursos de Administração de Mastella (2005). Na segunda etapa, pesquisaram-se as características intraempreendedoras dos gestores a partir da adaptação do questionário de Dornelas (2003), já aplicado e validado pela pesquisa de Walter et. al (2005) que, por sua vez, investigou o perfil dos gestores de cursos de Administração de quinze IES que constituem a Associação Catarinense das Fundações Educacionais (ACAFE) localizada no Vale do Itajaí em Santa Catarina. Também se pesquisaram, na terceira etapa do questionário, por meio de método qualitativo, as principais ações dos gestores. Segundo Oliveira (2001), a pesquisa qualitativa pode ser utilizada para estudos dirigidos à análise de atitudes, motivações, expectativas e valores.

$\mathrm{O}$ segundo questionário investigou as características intraempreendedoras dos gestores na opinião dos superiores imediatos desses gestores. Esse questionário foi modificado de Walter et al. (2007), que o adaptou de Dornelas (2003) para investigar as características intraempreendedoras dos gestores na opinião dos próprios gestores.

A população desta pesquisa constituiu-se dos gestores dos cursos de graduação em Ciências Contábeis da região oeste do Paraná. Direcionou-se a pesquisa aos nove gestores responsáveis por onze cursos de Ciências Contábeis de seis IES, distribuídos em 11 campi. As IES pesquisadas foram: Centro de Ensino Superior de Foz do Iguaçu (CESUFOZ), Faculdade de Ciência e Tecnologia (FACITEC), Universidade Estadual do Oeste do Paraná (UNIOESTE), União Pan-Americana de Ensino (UNIPAN), Universidade Paranaense (UNIPAR) e União Educacional de Cascavel (UNIVEL). Os superiores dos gestores consistem em sete diretores de centro ou geral.

Anteriormente ao envio dos questionários, realizaram-se contatos telefônicos com os pesquisados. Após o primeiro contato com os gestores e seus superiores, enviaram-se, por e-mail, os questionários. No decorrer do período em que se realizou a coleta de dados, se estabeleceram novos contatos telefônicos com o intuito de elevar o índice de respostas e, consequentemente, a qualidade 
desta pesquisa. Obteve-se, ao final, um significativo retorno, totalizando 100\% de questionários dos gestores de curso e $77,8 \%$ dos superiores.

Realizou-se a análise dos dados dos questionários respondidos pelos gestores dos cursos por meio de três métodos distintos, um para cada etapa do questionário. Na primeira etapa, para revelar o perfil atual desses gestores, realizaram-se análises das características dos mesmos, relacionadas à frequência de determinadas questões, como faixa etária, sexo, nomenclatura utilizada para o cargo de gestor de curso, titulação do gestor de curso, tempo de atuação como gestor e como docente, frequência com que executa determinadas ações integrantes dos colegiados de cursos, decisões tomadas pelos colegiados e tempo de existência dos cursos de Administração.

$\mathrm{Na}$ segunda etapa, que se refere ao teste do perfil intraempreendedor ou empreendedor corporativo, analisaram-se as características intraempreendedoras, segundo a autoavaliação dos gestores de curso. Classificaram-se os gestores de acordo com a pontuação atingida no teste, sendo que os gestores que alcançaram entre 90 e 119 pontos foram considerados, conforme Dornelas (2003), detentores de algumas características intraempreendedoras e os que atingiram 120 pontos, possuidores de características comuns aos intraempreendedores. Essa segunda etapa caracterizou-se como uma autoavaliação do gestor referente às características reunidas em cinco dimensões: a) comprometimento e determinação; b) ter obsessão pelas oportunidades; c) tolerância ao risco, ambiguidade e incertezas; d) criatividade, autoconfiança e habilidade de adaptação; e e) motivação e superação - divididas em três blocos distintos, distribuídos em colunas: o primeiro relaciona-se à importância que as IES atribuem a determinadas características dos gestores; o segundo, ao desempenho que sua instituição espera; e o terceiro, à autoavaliação atual do desempenho do gestor.

$\mathrm{Na}$ terceira etapa, analisaram-se as ações desenvolvidas pelos gestores e consideradas por eles as mais relevantes. Categorizaram-se tais ações em 13 dimensões por meio de análise qualitativa e se fez a representação das mesmas em gráficos, de acordo com a frequência, comparando com o resultado da segunda etapa do questionário, isto é, com a autoavaliação.

Analisou-se o questionário respondido pelos superiores dos gestores referente à avaliação do perfil intraempreendedor dos gestores de curso da mesma forma que a segunda etapa do questionário de autoavaliação dos gestores de curso.

Para o tratamento dos dados, utilizou-se planilha eletrônica (Excel) e o programa estatístico software SPSS. Para cruzar os resultados obtidos sobre as características intraempreendedoras dos gestores de curso nas duas amostras pesquisadas (gestores e superiores dos gestores) aplicou-se o teste U, de Mann-Withney, considerado um dos mais poderosos testes não-paramétricos utilizado como alternativa ao teste $t$ da estatística paramétrica (SIEGEL, 1975). Já para analisar a consistência interna dos resultados de cada dimensão, efetuou-se o cálculo do alfa de Cronbach.

\section{ANÁLISE E INTERPRETAÇÃO DOS DADOS}

A análise dos dados está dividida em três seções. A primeira refere-se ao perfil do gestor do curso; a segunda, às ações mais importantes realizadas por esses gestores; e a terceira, às suas características intraempreendedoras.

\subsection{O perfil do gestor do curso de ciências contábeis}

Nesta seção, apresenta-se a descrição dos dados pessoais, das características e das atividades dos gestores.

A respeito da faixa etária dos gestores, $11,1 \%$ têm idade entre 21 e 30 anos; $11,1 \%$, de 31 a 40 anos; 33,3\%, de 41 a 50 anos; e 44,4\%, de 51 a 60 anos. Em relação ao gênero, $100 \%$ dos gestores são homens. Quanto à nomenclatura atribuída ao cargo dos gestores responsáveis pelos cursos, em 11,1\% da IES, é de Chefe de Departamento; e em 88,9\%, de Coordenador de Curso. O Gráfico 1 apresenta a formação dos gestores dos cursos de Ciências Contábeis da região oeste do Paraná. 


\section{Formação do Gestor do Curso}

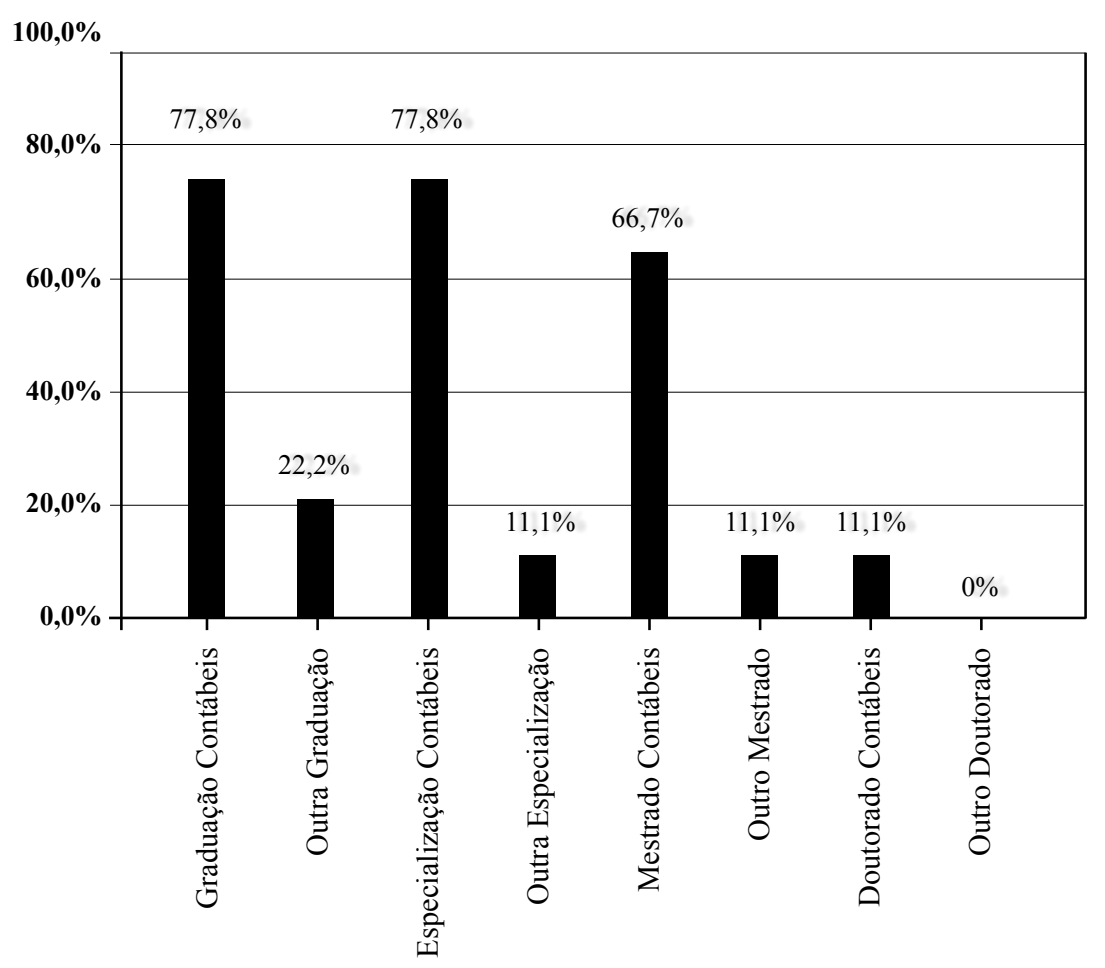

\section{Gráfico 1 - Formação dos Gestores dos Cursos}

Conforme os dados do Gráfico 1, a maioria dos gestores de cursos das IES pesquisadas possui formação na área de atuação, o que comprova o alinhamento com as diretrizes do MEC. Os dados mostram que $67 \%$ dos gestores têm o título de mestre em Ciências Contábeis e que apenas $11 \%$ possuem doutorado.

O tempo de atuação dos gestores e o tempo de existência dos cursos são mostrados na Tabela 1.

Tabela 1 - Tempo de atuação dos gestores de curso e tempo de existência dos cursos

\begin{tabular}{|c|c|c|c|c|c|}
\hline \multicolumn{2}{|c|}{$\begin{array}{c}\text { a) Atuação anterior como gestor em } \\
\text { outras IES }\end{array}$} & \multicolumn{2}{|c|}{ b) Atuação como gestor na IES atual } & \multicolumn{2}{|c|}{$\begin{array}{c}\text { c) Carga horária semanal dedicada } \\
\text { à gestão de curso }\end{array}$} \\
\hline Nenhum & $55,6 \%$ & Menos de 1 & $33,3 \%$ & Até 10 horas & $0 \%$ \\
\hline 1 ano & $11,1 \%$ & 1 ano & $0 \%$ & Até 20 horas & $66,7 \%$ \\
\hline 2 anos & $11,1 \%$ & 2 anos & $22,2 \%$ & Até 30 horas & $22,2 \%$ \\
\hline 3 anos & $0 \%$ & 3 anos & $22,2 \%$ & Até 40 horas & $11,1 \%$ \\
\hline 4 anos & $0 \%$ & 4 anos & $11,1 \%$ & Acima de 40 & $0 \%$ \\
\hline 5 anos & $11,1 \%$ & 5 anos & $0 \%$ & \multirow{2}{*}{\multicolumn{2}{|c|}{ d) Tempo de existência dos cursos }} \\
\hline 6 anos & $0 \%$ & 6 anos & $0 \%$ & & \\
\hline 7 anos & $0 \%$ & 7 anos & $0 \%$ & Até 5 anos & $22,2 \%$ \\
\hline 8 anos & $0 \%$ & 8 anos & $0 \%$ & 6 a 10 anos & $22,2 \%$ \\
\hline 9 anos & $0 \%$ & 9 anos & $0 \%$ & 11 a 20 anos & $11,1 \%$ \\
\hline 10 anos & $0 \%$ & 10 anos & $0 \%$ & 21 a 30 anos & $22,2 \%$ \\
\hline Acima de 10 & $11,1 \%$ & Acima de 10 & $11,1 \%$ & 31 a 40 anos & $22,2 \%$ \\
\hline Sem Resposta & $0 \%$ & Sem Resposta & $0 \%$ & Acima de 40 anos & $0 \%$ \\
\hline
\end{tabular}


De acordo com a primeira questão da Tabela 1, 55,6\% dos gestores iniciaram atuação de gestão de IES na qual se encontram vinculados atualmente, ou seja, não possuem experiência anterior como gestores. Quanto ao tempo de atuação dos gestores no cargo atual, a questão 2 apresentada na Tabela 1 aponta que $88,8 \%$ deles atuam há menos de 5 anos, o que contrasta com os $11,1 \%$ que atuam há mais de 10 anos.

No que tange à carga horária de dedicação à gestão do curso, a Tabela 1 mostra que $66,7 \%$ dos gestores têm dedicação de até 20 horas semanais. Conforme política do INEP, esse dado é preocupante e corrobora a pesquisa de Marra e Mello (2003) e de Kanan e Zanelli (2003) sobre a problemática da conciliação das atividades administrativas com as atividades docentes. O pouco tempo de dedicação à coordenação do curso pode repercutir negativamente nos resultados das atividades de gestão, pois lecionar e, ao mesmo tempo, gerir um curso de graduação acarreta uma sobrecarga de trabalho, podendo, consequentemente, dificultar o relacionamento com docentes, funcionários e superiores, além de prejudicar a saúde do ambiente de trabalho. Observa-se, ainda, que 44\% desses cursos pesquisados existem há menos de dez anos e, 55\%, há mais dez anos. Na Tabela 2, pode-se observar a atuação dos gestores como docentes.

Tabela 2 - Atuação do gestor como docente

\begin{tabular}{|c|c|c|c|c|c|}
\hline \multicolumn{2}{|c|}{$\begin{array}{l}\text { a) Tempo de atuação como } \\
\text { docente na carreira }\end{array}$} & \multicolumn{2}{|c|}{$\begin{array}{l}\text { b) Tempo de atuação como docente } \\
\text { na IES atual }\end{array}$} & \multicolumn{2}{|c|}{$\begin{array}{c}\text { c) Carga horária semanal dedicada } \\
\text { à docência }\end{array}$} \\
\hline Menos de 1 & $0 \%$ & Menos de 1 & $11,1 \%$ & Até 10 horas & $33,3 \%$ \\
\hline 1 ano & $0 \%$ & 1 ano & $0 \%$ & Até 20 horas & $44,4 \%$ \\
\hline 2 anos & $0 \%$ & 2 anos & $0 \%$ & Até 30 horas & $0 \%$ \\
\hline 3 anos & $11,1 \%$ & 3 anos & $22,2 \%$ & Até 40 horas & $11,1 \%$ \\
\hline 4 anos & $11,1 \%$ & 4 anos & $0 \%$ & Acima de 40 & $0 \%$ \\
\hline 5 anos & $0 \%$ & 5 anos & $0 \%$ & Dedicação exclusiva & $11,1 \%$ \\
\hline 6 anos & $11,1 \%$ & 6 anos & $11,1 \%$ & Nenhuma & $0 \%$ \\
\hline 7 anos & $0 \%$ & 7 anos & $0 \%$ & \multirow{2}{*}{\multicolumn{2}{|c|}{ d) Atuação como docente em outra IES }} \\
\hline 8 anos & $0 \%$ & 8 anos & $0 \%$ & & \\
\hline 9 anos & $0 \%$ & 9 anos & $11,1 \%$ & Não & $55,6 \%$ \\
\hline 10 anos & $0 \%$ & 10 anos & $0 \%$ & Sim & $33,3 \%$ \\
\hline Acima de 10 & $66,7 \%$ & Acima de 10 & $44,4 \%$ & Sem Resposta & $11,1 \%$ \\
\hline
\end{tabular}

Quanto à primeira questão da Tabela 2, é possível constatar que 66,7\% dos gestores possuem grande experiência enquanto docentes, visto que atuam há mais de dez anos. Na segunda questão, observa-se que, dos $66,7 \%$ dos gestores que atuam há mais de dez anos na carreira, $44,4 \%$ atuam esse período na IES à qual se encontram vinculados atualmente. A carga horária semanal dedicada à docência, para 77,7\% dos pesquisados, é de, no máximo, 20 horas. Pode-se observar, igualmente, que $55,6 \%$ dos gestores atuam como professores somente na IES onde exercem cargo de gestão.

Investigou-se, também, a participação dos agentes envolvidos no colegiado do curso. Como resultado, identificou-se alta participação de alunos e de professores (100\%) e de coordenadores (78\%) nos colegiados, como também uma relativa participação de diretores e de funcionários (11\%). Isso demonstra que as instituições pesquisadas estão cumprindo a recomendação do MEC em relação à presença de um colegiado de curso que represente os vários atores do cenário institucional e que exerçam as funções administrativas de direção e coordenação. 
A Tabela 3 mostra as decisões tomadas pelo colegiado de curso.

Tabela 3 - Decisões tomadas pelo colegiado de curso

\begin{tabular}{l|l}
\hline \multicolumn{2}{l}{ Decisões tomadas pelo colegiado de curso } \\
\hline Decisões relativas a conteúdos programáticos & $100 \%$ \\
\hline Decisões relativas a tipos de avaliações pedagógicas & $100 \%$ \\
\hline Decisões relativas a atividades de extensão & $89 \%$ \\
\hline Decisões relativas à matriz curricular e análise curricular & $78 \%$ \\
\hline Decisões relativas à divulgação do curso no mercado & $78 \%$ \\
\hline Decisões relativas a parcerias com empresas da região & $78 \%$ \\
\hline Decisões relativas a atividades de pesquisa & $67 \%$ \\
\hline Outras decisões & $56 \%$ \\
\hline Decisões relativas à contratação de professores & $44 \%$ \\
\hline Decisões relativas à gestão financeira do curso & $22 \%$ \\
\hline
\end{tabular}

Quanto às decisões tomadas pelo colegiado de curso, verifica-se que as relativas a conteúdos programáticos e a tipos de avaliações pedagógicas possuem maior percentual de respostas, significando que o colegiado de curso tem maior poder de decisão sobre as questões pedagógicas em relação às questões administrativas.

A Tabela 4 apresenta a frequência das ações executadas pelos gestores.

Tabela 4 - Ações executadas pelos gestores dos cursos de Ciências Contábeis

Frequência de ações executadas pelos gestores do curso de Ciências Contábeis

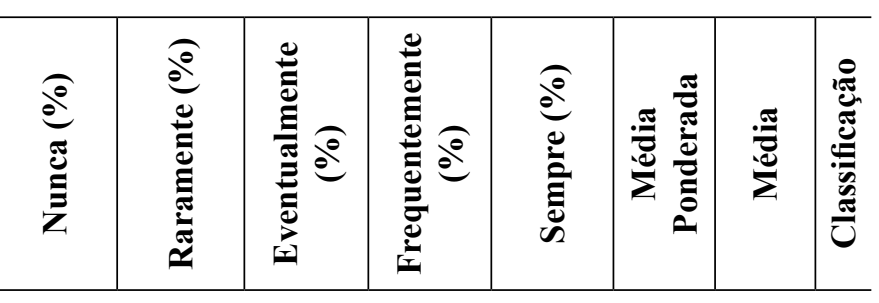

\section{AÇÕES VOLTADAS AO MERCADO}

\begin{tabular}{|c|c|c|c|c|c|c|c|c|}
\hline $\begin{array}{l}\text { Fazem visitas às empresas para conhecer o perfil profissio- } \\
\text { nal desejado. }\end{array}$ & $11,1 \%$ & $11,1 \%$ & $33,3 \%$ & $44,4 \%$ & $0 \%$ & 2,11 & \multirow{6}{*}{2,37} & \\
\hline $\begin{array}{l}\text { Fazem pesquisa de mercado a fim de responder de maneira } \\
\text { adequada à demanda. }\end{array}$ & $11,1 \%$ & $22,2 \%$ & $33,3 \%$ & $11,1 \%$ & $11,1 \%$ & 1,67 & & \\
\hline Fazem sondagem do ambiente frente às IES concorrentes. & $22,2 \%$ & $22,2 \%$ & $0 \%$ & $33,3 \%$ & $44,4 \%$ & 3,00 & & 7 \\
\hline $\begin{array}{l}\text { Fazem palestras e workshops com empresários da região onde } \\
\text { atua. }\end{array}$ & $11,1 \%$ & $22,2 \%$ & $33,3 \%$ & $11,1 \%$ & $11,1 \%$ & 1,67 & & \\
\hline Acompanham a inserção de alunos no mercado de trabalho. & $11,1 \%$ & $0 \%$ & $11,1 \%$ & $33,3 \%$ & $44,4 \%$ & 3,00 & & \\
\hline Representam externamente a instituição & $11,1 \%$ & $0 \%$ & $11,1 \%$ & $55,6 \%$ & $22,2 \%$ & 2,78 & & \\
\hline \multicolumn{9}{|l|}{ PESQUISA E EXTENSÃO } \\
\hline Promovem atividades de extensão na comunidade. & $0 \%$ & $11,1 \%$ & $11,1 \%$ & $33,3 \%$ & $44,4 \%$ & 3,11 & \multirow{3}{*}{2,96} & \multirow{3}{*}{5} \\
\hline Envolvem seus alunos em ações sociais na comunidade. & $0 \%$ & $11,1 \%$ & $33,3 \%$ & $44,4 \%$ & $11,1 \%$ & 2,55 & & \\
\hline Estimulam o desenvolvimento da pesquisa na IES. & $0 \%$ & $0 \%$ & $22,2 \%$ & $33,3 \%$ & $44,4 \%$ & 3,22 & & \\
\hline \multicolumn{9}{|l|}{ AÇÕES FOCADAS NOS ALUNOS } \\
\hline Atendimento aos alunos & $0 \%$ & $0 \%$ & $0 \%$ & $0 \%$ & $100 \%$ & 4,00 & 4,00 & 1 \\
\hline \multicolumn{9}{|l|}{ AÇÕES FOCADAS NOS PROFESSORES } \\
\hline Atendimento a professores & $0 \%$ & $0 \%$ & $0 \%$ & $11,1 \%$ & $89,9 \%$ & 3,93 & 3,93 & 2 \\
\hline
\end{tabular}




\begin{tabular}{l|c|c|c|c|c|c|c|c}
\hline Planejamento estratégico do curso & $0 \%$ & $0 \%$ & $0 \%$ & $44,4 \%$ & $55,6 \%$ & 3,56 & 3,59 & 4 \\
\hline Elaboração do PPP da IES & $0 \%$ & $0 \%$ & $22,2 \%$ & $11,1 \%$ & $66,7 \%$ & 3,45 & \\
\hline Acompanhamento do PPP da IES & $0 \%$ & $0 \%$ & $0 \%$ & $22,2 \%$ & $77,8 \%$ & 3,78 & \\
\hline AÇÕES VOLTADAS À CAPACITAÇÃO DE DOCENTES & $0 \%$ & $0 \%$ & $0 \%$ & $33,3 \%$ & $66,7 \%$ & 3,67 & 2,94 & 6 \\
\hline Desenvolvimento de atividades didático-pedagógicas & $0 \%$ & $22,2 \%$ & $33,3 \%$ & $44,4 \%$ & $0 \%$ & 2,22 & \\
\hline Promoção de treinamentos pedagógicos aos docentes do curso & $0 \%$ & & \\
\hline REUNIÕES & $0 \%$ & $0 \%$ & $11,1 \%$ & $11,1 \%$ & $77,8 \%$ & 3,67 & 3,67 & 3 \\
\hline
\end{tabular}

As questões referentes a ações dos gestores, apresentadas na Tabela 4, foram submetidas ao cálculo da média ponderada e agrupadas em sete dimensões: ações voltadas ao mercado; pesquisa e extensão; aos alunos; aos professores; às atividades de Planejamento Político-Pedagógico; à capacitação de docentes; e a reuniões. Cada dimensão gerou uma média, e essas médias foram ordenadas. A maior frequência das ações dos gestores se encontra ordenada da seguinte forma: ações focadas nos alunos, nos professores, em reuniões, em atividades de PPP, em capacitação docente, em pesquisa e extensão e no mercado. Nota-se ainda que a ação mais realizada é o atendimento a alunos, seguida do atendimento a professores e, na sequência, o acompanhamento do PPP da IES. Como se pode perceber, essas atividades estão relacionadas às atribuições dos gestores de curso destacadas por Grunow et al. (2005), como coordenar atividades de ensino, deliberar sobre representações de alunos e observar as normas da IES.

Esta primeira etapa identificou o perfil dos gestores do oeste do Paraná, em que se evidenciaram a grande experiência dos gestores como professores, o contraste entre os gestores que atuam no cargo há menos de 5 anos e os que atuam há mais de 10 anos e a reduzida carga horária de dedicação dos gestores ao cargo. Na próxima etapa, se apresentam as ações consideradas mais importantes pelos gestores.

\subsection{Ações consideradas mais importantes pelos gestores}

No Gráfico 2, mostram-se as ações que os gestores consideram mais importantes.

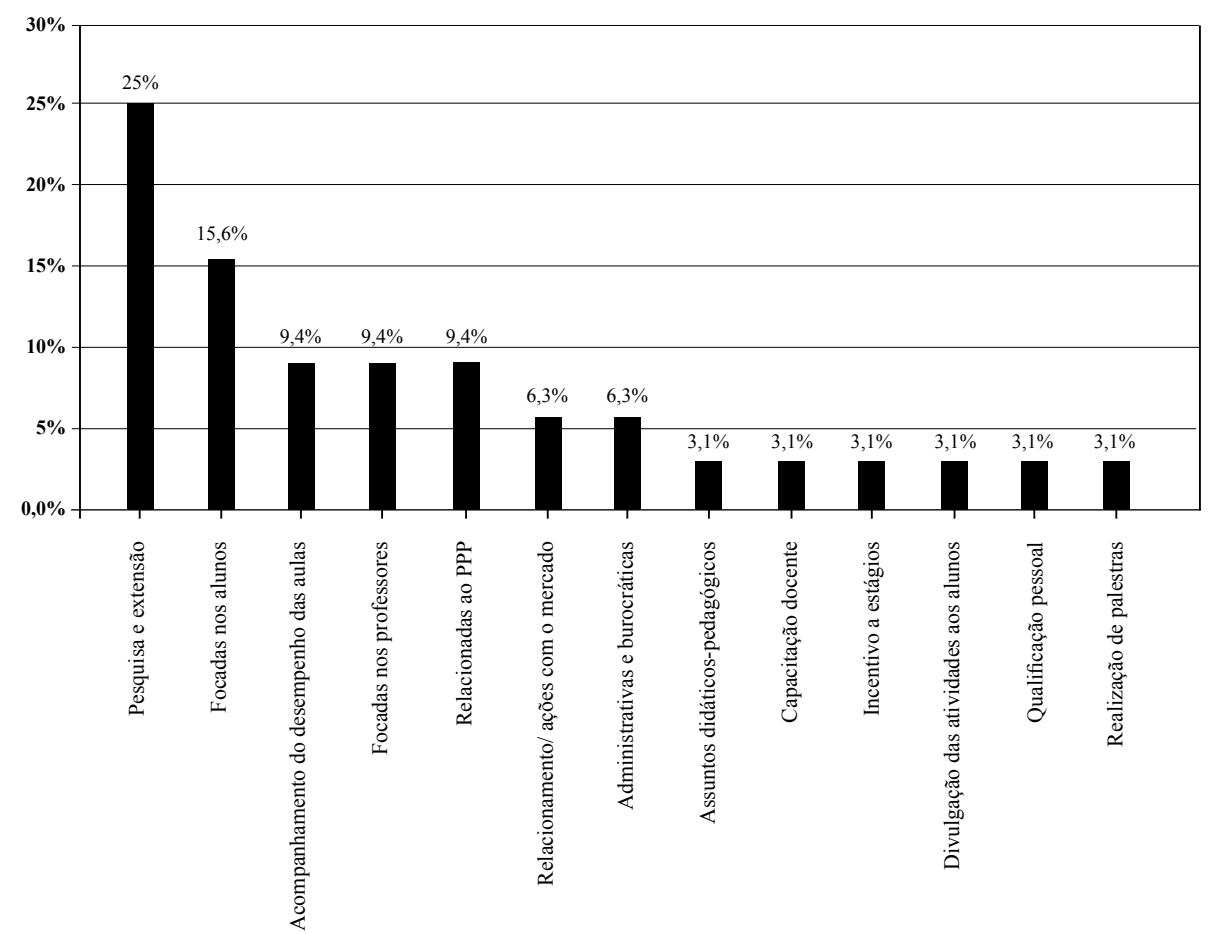

Gráfico 2 - Ações consideradas mais importantes pelos gestores 
No Gráfico 2, mostram-se as ações realizadas pelos gestores e consideradas as mais importantes, obtidas por meio de uma questão subjetiva descrita na terceira etapa do questionário e agrupadas em 13 dimensões. Os índices indicados no Gráfico 2 correspondem ao número de ações citadas em cada dimensão no que tange ao número total de ações citadas.

Contrapondo os dados do Gráfico 2 aos dados da Tabela 4, observa-se que coincidem os resultados das dimensões referentes às ações focadas nos alunos, mais citadas nas respostas objetivas (Tabela 4) e segunda colocada nas subjetivas (Gráfico 2); ações focadas nos professores, segunda colocada na Tabela 4 e quarta no Gráfico 2. A dimensão relacionada às ações voltadas à pesquisa e extensão foi citada como a mais importante pelos gestores (Gráfico 2), porém aparece somente como quinta colocada entre as ações que os gestores mais realizam (Tabela 4). Nesse sentido, observa-se que os gestores atuam mais frequentemente na coordenação do ensino e menos nas atividades de pesquisa e de extensão (GRUNOW, et al. 2005). Isso pode estar relacionado também ao fato de que parte das IES pesquisadas consiste em faculdades e centros universitários e não em universidades, de forma que o foco em pesquisa e extensão das próprias instituições seja menor.

Nesta etapa, apresentaram-se as ações que os gestores consideram mais importantes e se fez a comparação destas com as ações mais realizadas por eles, apresentadas na etapa anterior. Na próxima seção, descrever-se-ão e analisar-se-ão os resultados do perfil intraempreendedor dos gestores pesquisados.

\subsection{Características intraempreendedoras dos gestores}

Nesta seção, apresenta-se a análise das características intraempreendedoras dos gestores. De acordo com os resultados do teste do perfil intraempreendedor ou do empreendedor corporativo de Dornelas (2003), a média geral atingida pelos gestores foi de 133,4 pontos, o que permite, com base no autor, classificar as características constatadas como características comuns a intraempreendedores, pois ultrapassam 120 pontos. De acordo com o teste de normalidade, os dados apresentaram distribuição não normal. Aliando esse resultado ao pequeno tamanho da amostra, é indicado o uso de estatística não paramétrica em detrimento da paramétrica. Optou-se pela utilização do teste U de Mann-Withney.

A Tabela 5 apresenta os resultados do teste U de Mann-Withney.

Tabela 5 - Análise geral a partir do teste U de Mann-Whitney

\begin{tabular}{|c|c|c|c|c|c|}
\hline Variáveis & $\begin{array}{c}\text { Soma dos } \\
\text { postos } \\
\text { (Gestores) }\end{array}$ & $\begin{array}{c}\text { Soma dos } \\
\text { postos (Su- } \\
\text { periores) }\end{array}$ & Discrepância & $\begin{array}{l}\text { Significância } \\
\text { (Bi-caudal) }\end{array}$ & $\begin{array}{l}\text { Prioridade por } \\
\text { significância da } \\
\text { discrepância }\end{array}$ \\
\hline \multicolumn{6}{|l|}{ Comprometimento e determinação } \\
\hline Pró-atividade na tomada de decisão & 79,5 & 40,5 & 39 & 0,032 & 5 \\
\hline Tenacidade/Obstinação & 84,5 & 35,5 & 49 & 0,013 & 2 \\
\hline Disciplina e dedicação & 74,0 & 46,0 & 28 & 0,206 & Não-significante \\
\hline Persistência na resolução de problemas & 74,0 & 46,0 & 28 & 0,206 & Não-significante \\
\hline Disposição ao sacrifício para atingir metas & 80,0 & 40,0 & 40 & 0,046 & 8 \\
\hline Imersão nas atividades que desenvolve & 68,0 & 52,0 & 16 & 0,605 & Não-significante \\
\hline \multicolumn{6}{|l|}{ Obsessão pelas oportunidades } \\
\hline $\begin{array}{l}\text { Procurar ter conhecimento das necessidades } \\
\text { dos alunos }\end{array}$ & 79,0 & 41,0 & 38 & 0,054 & Não-significante \\
\hline Dirigir-se pelo mercado & 65,0 & 55,0 & 10 & 0,901 & Não-significante \\
\hline $\begin{array}{l}\text { Ter obsessão em criar valor e satisfazer os } \\
\text { alunos }\end{array}$ & 79,5 & 40,5 & 39 & 0,060 & Não-significante \\
\hline \multicolumn{6}{|l|}{ Tolerância ao risco, ambigüidade e incertezas } \\
\hline Capacidade de assumir riscos calculados & 83,0 & 37,0 & 46 & 0,013 & 2 \\
\hline
\end{tabular}




\begin{tabular}{l|c|c|c|c|c}
\hline Capacidade de minimizar os riscos & 76,0 & 44,0 & 32 & 0,115 & Não-significante \\
\hline $\begin{array}{l}\text { Tolerância a incertezas e à falta de estrutu- } \\
\text { ra }\end{array}$ & 52,5 & 52,5 & 0 & 1,00 & Não-significante \\
\hline Tolerância ao estresse e conflitos & 67,0 & 53,0 & 14 & 0,619 & Não-significante \\
\hline $\begin{array}{l}\text { Habilidade em resolver problemas e inte- } \\
\text { grar soluções }\end{array}$ & 80,5 & 39,5 & 41 & 0,041 & 7 \\
\hline
\end{tabular}

'Criatividade, autoconfiança e habilidade de adaptação

\begin{tabular}{l|c|c|c|c|c} 
'Criatividade, autoconfiança e habilidade de adaptação \\
\hline $\begin{array}{l}\text { Não ser convencional, ter mente aberta e } \\
\text { ser pensador }\end{array}$ & 80,5 & 39,5 & 41 & 0,037 & 6 \\
\hline Não se conformar com o status quo & 84,0 & 36,0 & 48 & 0,015 & 3 \\
\hline $\begin{array}{l}\text { Ter habilidade para se adaptar a novas } \\
\text { situações }\end{array}$ & 73,0 & 47,0 & 26 & 0,252 & Não-significante \\
\hline Não ter medo de falhar & 76,0 & 44,0 & 32 & 0,134 & Não-significante \\
\hline $\begin{array}{l}\text { Ter habilidade para definir conceitos e de- } \\
\text { talhar idéias }\end{array}$ & 70,0 & 50,0 & 20 & 0,428 & Não-significante \\
\hline
\end{tabular}

\begin{tabular}{l|c|c|c|c|c}
\hline Motivação e superação & \multicolumn{5}{l}{} \\
\hline Orientar-se por metas e resultados & 67,5 & 37,5 & 30 & 0,032 & 5 \\
\hline $\begin{array}{l}\text { Ser dirigido pela necessidade de crescimen- } \\
\text { to pessoal e de atingir melhores resultados }\end{array}$ & 64,0 & 41,0 & 23 & 0,113 & Não-significante \\
\hline Preocupar-se com status e poder & 55,0 & 50,0 & 5 & 0,740 & Não-significante \\
\hline Ter autoconfiança & 68,5 & 36,5 & 32 & 0,026 & 4 \\
\hline $\begin{array}{l}\text { Ter conhecimento (percepção) de suas for- } \\
\text { ças e fraquezas }\end{array}$ & 60,0 & 45,0 & 15 & 0,293 & Não-significante \\
\hline Ter senso de humor & 58,0 & 47,0 & 11 & 0,424 & Não-significante \\
\hline Ter iniciativa & 71,5 & 33,5 & 38 & 0,009 & 1 \\
\hline Ter autocontrole & 60,0 & 45,0 & 15 & 0,293 & Não-significante \\
\hline Transmitir integridade e confiabilidade & 60,5 & 44,5 & 16 & 0,244 & Não-significante \\
\hline Ser paciente e saber ouvir & 54,0 & 51,0 & 3 & 0,833 & Não-significante \\
\hline $\begin{array}{l}\text { Ter capacidade de construir times e traba- } \\
\text { lhar em equipe }\end{array}$ & 66,0 & 39,0 & 27 & 0,061 & Não-significante \\
\hline
\end{tabular}

Percebe-se, na Tabela 5, que as características mais presentes na autoavaliação dos gestores foi tenacidade/obstinação; não se conformar com o status quo; e capacidade de assumir riscos calculados. A tenacidade e obstinação estão relacionadas à dedicação (PINCHOT, 1989). Não se conformar com o status quo também remete à característica de necessidade de agir (PINCHOT, 1989). A capacidade de assumir riscos indica a habilidade de administração de riscos e de superar erros e fracassos quando estes ocorrem (PINCHOT, 1989). Em contraposição, a característica que os gestores consideraram menos presente foi tolerância a incertezas e à falta de estrutura, o que pode indicar dificuldade de se adaptar de acordo com os recursos existentes e necessidade de apoio (KURATKO; MONTAGNO; HORNSBY, 1990; WALTER et al., 2005).

Já os superiores dos gestores indicaram como mais presente a característica de dirigir-se pelo mercado, o que se relaciona à identificação de oportunidades do mercado para gerar novas oportunidades (SCHUMPETER, 1982), e menos presente a de ter iniciativa, o que pode indicar novamente a necessidade de apoio dos gestores (KURATKO; MONTAGNO; HORNSBY, 1990; WALTER et al., 2005).

De acordo com o teste U de Mann-Whitney, consideram-se significativas as discrepâncias que apresentaram probabilidades associadas à estatística $U$ inferiores a 0,05 ; as demais (superiores a 0,05 ) são consideradas estatisticamente não significantes.

Observa-se, na Tabela 5, que, com a aplicação do teste U de Mann-Whitney, nas duas amostras independentes pesquisadas (gestores e superiores dos gestores), as variáveis que apresentaram discrepância significativa estatisticamente foram: proatividade na tomada de decisão; tenacidade/obstina- 
ção; disposição ao sacrifício para atingir metas; capacidade de assumir riscos calculados; habilidade em resolver problemas e integrar soluções; não ser convencional, ter mente aberta e ser pensador; não se conformar com o status quo; orientar-se por metas e resultados; ter autoconfiança; e ter iniciativa. Ressalta-se, também, que, em todas as variáveis citadas, o desempenho declarado pelo gestor foi mais elevado do que o constatado pelo seu superior.

As variáveis apontadas no parágrafo anterior foram priorizadas considerando o índice de significância das discrepâncias entre as duas amostras: quanto mais próximas a zero as probabilidades associadas à estatística $U$, maior a prioridade. Tal discrepância reflete um desalinhamento estratégico entre a visão dos gestores e de seus superiores em relação ao desempenho atual das variáveis pesquisadas. Dessa forma, quanto maior a prioridade destacada na Tabela 5 , maior o desalinhamento entre essas visões. Assim, por ordem de prioridade, o desalinhamento estratégico é mais crítico nas variáveis: ter iniciativa; capacidade de assumir riscos calculados; não se conformar com o status quo; ter autoconfiança; orientar-se por metas e resultados; não ser convencional, ter mente aberta e ser pensador; habilidade em resolver problemas e integrar soluções; e disposição ao sacrifício para atingir metas.

Pretendendo analisar a consistência interna dos resultados de cada dimensão, se efetuou o cálculo do alfa de Cronbach. Esse coeficiente, muito utilizado na área de Estudos Sociais (HAIR JR. et al., 2005; MALHOTRA, 2001; PASQUALI, 2002), estabelece uma medida de validade convergente do construto, sendo que, quanto mais próximo de 1,00, menor a expectativa de erro e, consequentemente, maior a confiabilidade do instrumento. Mostram-se os resultados do alfa de Cronbach na Tabela 6.

\section{Tabela 6 - Alfa de Cronbach}

\begin{tabular}{l|c}
\hline \multicolumn{1}{c|}{ Dimensões } & Alfa de Cronbach \\
\hline Comprometimento e determinação & 0,694 \\
\hline Ter obsessão pelas oportunidades & 0,621 \\
\hline Tolerância ao risco, ambiguidade e incertezas & 0,711 \\
\hline Criatividade, autoconfiança e habilidade de adaptação & 0,876 \\
\hline Motivação e superação & 0,788 \\
\hline
\end{tabular}

Em relação à Tabela 6, observa-se que os coeficientes maiores que 0,6 apresentam um grau de fidelidade aceitável, revelando a validade das variáveis em relação às suas dimensões (NUNNALY, 1967). Observa-se, igualmente, que todas as dimensões apresentaram um coeficiente maior que 0,6 , com exceção da dimensão tolerância ao risco, ambiguidade e incertezas, que apresentou, inicialmente, um alfa de 0,528 , tendo a variável capacidade de assumir riscos calculados excluída, o coeficiente foi elevado para 0,711 .

\section{CONSIDERAÇÕES FINAIS}

Este estudo, que teve por objetivo identificar e analisar o perfil e as características intraempreendedoras dos gestores de cursos de graduação em Ciências Contábeis do oeste do Paraná, comprovou a aplicabilidade dos instrumentos de pesquisa e o método utilizado ao atingir seus objetivos.

Em relação ao perfil, 88,9\% dos gestores dos cursos são coordenadores, $44,4 \%$ estão na faixa etária entre 51 a 60 anos; são todos homens; 77,8\% possuem titulaçãoc de especialistas em Ciências Contábeis e $66,7 \%$, de mestres em Ciências Contábeis, tendo seu principal vínculo empregatício com a instituição na qual atuam. O tempo de dedicação à gestão de $66,7 \%$ dos gestores é de até 20 horas semanais e de atuação na docência, para 44,4\% desses gestores, é de, até, 20 horas semanais, fato que, para Marra e Mello (2003) e Kanan e Zanelli (2003), desperta preocupação quanto à conciliação das atividades devido ao tempo restrito de dedicação à coordenação do curso. 
As ações realizadas pelos gestores, ordenadas por frequência, são focadas nos alunos, nos professores, em reuniões, nas atividades de PPP, em pesquisa e extensão, em capacitação docente e no mercado. Contudo, as ações consideradas mais importantes pelos gestores são relacionadas à pesquisa e extensão; focadas nos alunos; acompanhamento do desempenho das aulas; focadas nos professores; relacionadas ao PPP; relacionamento/ações com o mercado; e atividades administrativas e burocráticas. Percebe-se que as ações mais desenvolvidas pelos gestores apresentam-se, em sua maioria, voltadas às ações internas, essencialmente ao atendimento de alunos e professores, fato que deveria ser objeto de reflexão nas IES, uma vez que pesquisa e extensão, apontada como a mais importante, por exemplo, poderia ser priorizada. Supõe-se, portanto, que a baixa carga horária de dedicação à coordenação do curso esteja impossibilitando ações mais proativas e relevantes do ponto de vista pedagógico. No entanto, contrapondo este dado à baixa carga horária de dedicação à coordenação, supõe-se que esta possa ser um fator capaz de prejudicar a realização dessas atividades.

Em relação às características intraempreendoras apontadas por Dornelas (2003), ficou evidenciado o potencial dos gestores, dado que, na auto-avaliação, 100\% dos respondentes obtiveram pontuação entre 120 e 150 pontos, o que indica características comuns aos intraempreendedores ou empreendedores corporativos. Entretanto, existe um potencial a ser explorado, tendo em vista que a média dos gestores ficou em 133,4 pontos, abaixo da pontuação máxima, que é de 150 pontos.

No que se refere à discrepância entre a autoavaliação dos gestores e a avaliação dos superiores quanto às variáveis propostas no teste de perfil intraempreendedor de Dornelas (2003), as variáveis ter iniciativa; tenacidade/obstinação; capacidade de assumir riscos calculados; não se conformar com o status quo; ter autoconfiança; proaatividade na tomada de decisão; orientar-se por metas e resultados; não ser convencional, ter mente aberta e ser pensador; habilidade em resolver problemas e integrar soluções; e disposição ao sacrifício para atingir metas apresentaram os maiores desalinhamentos estratégicos.

Observou-se uma tendência dos gestores em atribuir valores maiores às variáveis em sua autoavaliação, o que acarretou uma elevação dos postos médios indicados pelos gestores que, no geral, se apresentaram mais elevados do que os indicados pelos superiores. Apencas a variável tolerância a incertezas e à falta de estrutura apresentou o mesmo posto nas duas avaliações, e nenhum posto indicado pelos superiores se apresentou acima do dos gestores. Este resultado pode demonstrar uma tendência à superavaliação dos gestores em relação ao seu próprio desempenho atual.

Como conclusão, percebe-se a necessidade de maior clareza no diálogo entre os superiores e os gestores para um maior alinhamento em relação ao desempenho atual dos gestores. Percebe-se, igualmente, que questões como a conciliação entre a carga horária ensino/gestão ainda precisa ser aperfeiçoada para que possam ser atingidos melhores níveis de profissionalização na gestão universitária.

Além do perfil intraempreendedor e de uma atuação eficaz dos gestores, outro fator crucial para o sucesso da gestão das IES e da melhoria da qualidade de ensino, evidenciado por Kuratko, Montagno e Hornsby (1990), são as condições gerais proporcionadas pelas IES à atuação dos gestores, em termos de apoio às iniciativas, recursos e condições de trabalho. Sabe-se que existem limitações à atuação dos coordenadores que podem dificultar a realização de ações empreendedoras ou consideradas mais importantes para eles. Nesse sentido, a atuação de colegiados, de conselhos e de mantenedoras, bem com as regras existentes nas instituições de ensino superior podem limitar o escopo de ação dos gestores.

No tocante à importância desta pesquisa, avaliar o perfil intraempreendedor dos gestores dos cursos de Ciências Contábeis, por meio dos estudos de Dornelas (2003), Mastella (2005), Walter et al. (2005) e Walter et al. (2007), apresenta-se como possibilidade dce os gestores realizarem uma autoavaliação e reflexão no que se refere às suas ações de gestão e à perspectiva da IES quanto ao seu perfil e ações. Os resultados desta pesquisa possibilitam, também, que as IES reavaliem seus processos de modo a aperfeiçoarem suas ações gerenciais a fim de se tornarem mais eficazes, acarretando possíveis melhorias para a qualidade do ensino. Estes argumentos são reforçados por Peleias (2006, p. 219) que diz: "a gestão eficaz do currículo do curso superior em Ciências Contábeis permitirá que as instituições formem cidadãos profissionais aptos a enfrentarem uma realidade dinâmica e desafiadora". 
Conclui-se que, por meio da adaptação de Walter et al. (2005) e Walter et al. (2007) de dois questionários - o de Dornelas (2003), um dos poucos instrumentos que medem o perfil intraempreendedor, e o de Mastella (2005), de diagnóstico de gestão -, bem como da modificação do questionário de Walter et al. (2007) - baseado em Dornelas (2003), para possibilitar a verificação da opinião dos superiores dos gestores - é possível avaliar de forma inovadora o perfil intraempreendedor e as ações de gestores de cursos de Ciências Contábeis, sob a ótica da autoavaliação e da avaliação das IES.

\section{REFERÊNCIAS}

BARBIERI, J. C. (org). Organizações inovadoras: estudos e casos brasileiros. 2. ed. Rio de Janeiro: FGV, 2003. c

BOULTON, W. R.; CARLAND, J.; HOY, F. Differentiating entrepreneurs from small business owners: a conceptualization. Academy Management Review, v. 9, n. 2, p. 356-359, 1984.

DEGEN, Ronald J. O empreendedor: fundamentos da iniciativa empresarial. 3. ed. São Paulo: McGraw-Hill, 1989.

DORNELAS, J. C. A. Empreendedorismo corporativo: como ser empreendedor, inovar e se diferenciar em organizações estabelecidas. Rio de Janeiro: Elsevier, 2003.

FILION, L. J. Diferenças entre sistemas gerenciais de empreendedores e operadores de pequenos negócios.Revista de Administração de Empresas, São Paulo, v. 39, n. 4, p. 6-20, out./dez. 1999.

GIL, A. C. Métodos e técnicas de pesquisa social. 5. ed. São Paulo: Atlas, 1999.

GRILLO, Antonio Niccolo. Desenvolvimento de pessoal nas universidades: em busca da qualidade do ensino superior. Florianópolis: Insular: 1996.

GRUNOW, A.; SABADIN, A. L.; FASSINA, P. H.; DOMINGUES, M. J. C. de S. Análise do perfil dos gestores do curso de Ciências Contábeis das IES -Instituições de Ensino Superior do estado de Santa Catarina. In: CONGRESSO USP DE CONTROLADORIA E CONTABILIDADE, 05., 2005, São Paulo. Anais..., 2005.

HAIR JR; J. F; BABIN, B; MONEY, A. H; SAMOUEL, P. Fundamentos de métodos de pesquisa em administração. Porto Alegre: Bookman, 2005.

HORNSBY, J. S; NAFFZIGER, D. W; KURATKO, D. F; MONTAGNO, R.V. An interactive model of the corporate entrepreneurship process. Entrepreneurship: Theory and Practice, Malden, v. 17, n. 2, 1993. Disponível em: <http://www.allbusiness.com/periodicals/article/382098-1.html> Acesso em: 01 jun. 2006.

KANAN, L. A.; ZANELLI, J. C. O processo de vinculação de coordenadores de curso com seu trabalho e com a universidade. In: ENCONTRO NACIONAL DE PROGRAMAS DE PÓS-GRADUAÇÃO EM ADMINISTRAÇÃO, 17., 2003, Curitiba. Anais... Rio de Janeiro: ANPAD, 2003.

KURATKO, D. F.; MONTAGNO, R. V.; HORNSBY, J. S. Developing an intrapreneurial assessment instrument for an effective corporate entrepreneurial environment. Strategic Management Journal. Chichester, v. 11; n. 5, p. 49-58, 1990. 
KURATKO, Donald F.; HORNSBY, Jeffrey S; NAFFZIGER, Douglas. W; MONTAGNO, Ray V. Implement entrepreneurial thinking in established organizations. SAM Advanced Management Journal, Texas, v. 58, n. 1, p. 28-39, 1993.

MALHOTRA, N. K. Pesquisa de marketing: uma orientação aplicada. 3. ed. Porto Alegre: Bookman, 2001.

MARRA, A. V.; MELO, M. C. O. L. Docente-gerente: o cotidiano de chefes de departamento e coordenadores em uma Universidade Federal. In: ENCONTRO NACIONAL DE PROGRAMAS DE PÓSGRADUAÇÃO EM ADMINISTRAÇÃO, 27., 2003, Curitiba. Anais... Rio de Janeiro: ANPAD, 2003.

MASTELLA, A. S. Diagnóstico da gestão de cursos de administração em instituições de ensino superior privadas. Disponível em: $<\mathrm{http}$ :/www.angrad.org.br>. Acesso em: 10 maio 2005.

MCCLLELAND, D. A sociedade competitiva: realização e progresso social. Rio de Janeiro: Expressão e Cultura, 1972.

MEYER JR, V.. Novo contexto e as habilidades do administrador universitário. In: MEYER JR, Victor; MURPHY, Patrick (org.). Dinossauros, gazelas e tigres: novas abordagens da administração universitária. Um diálogo Brasil e EUA. Florianópolis: Insular, 2000.

MORAES, W. B. de. Efetividade organizacional na perspectiva de coordenadores de curso de graduação da PUC Minas: contribuições para a gestão de Instituições de Ensino Superior. In: ENCONTRO DA ASSOCIAÇÃO DOS DE PÓS-GRADUAÇÃO EM ADMINISTRAÇÃO, 28, 2004. Anais... Campinas, 2004.

NUNNALY, J. C. Psychometric theory. New York (NY): McGraw-Hill; 1970.

OLIVEIRA, S. L. Tratado de metodologia científica. São Paulo: Pioneira, 2001.

PASQUALI, L. Análise fatorial para pesquisadores. Brasília: UnB, 2002.

PELEIAS, I. R. (org.). Didática do ensino da contabilidade: aplicável a outros cursos superiores. São Paulo: Saraiva, 2006.

PINCHOT, G. Intrapreneuring: por que você não precisa deixar a empresa para tornar-se um empreendedor. São Paulo: Harbra, 1989.

SCHUMPETER, J. A. Teoria do desenvolvimento econômico: uma investigação sobre lucros, capital, crédito, juro e o ciclo econômico. 2. ed. São Paulo: Abril Cultural, 1982.

SILVA, O. L. da. O desempenho do coordenador de curso na sua linha de trabalho para atender a Resolução CNE no 10/2004. In: ENCONTRO NACIONAL DE COORDENADORES DO CURSO DE CIÊNCIAS CONTÁBEIS, 1, 2006. Anais... Disponível em: <http://www.cfc.org.br/uparq/oscar. pdf>. Acesso em: 10 jul. 2007.

SILVA, M. A.; MORAES, L. V. dos. Como os professores aprendem a dirigir unidades universitárias: o caso da UFSC. ENCONTRO NACIONAL DE PROGRAMAS DE PÓS-GRADUAÇÃO EM ADMINISTRAÇÃO, 27, 2003, Atibaia. Anais... Rio de Janeiro: ANPAD, 2003. 
SIEGEL, S. Estatística não-paramétrica para as ciências do comportamento. São Paulo: McGrawHill, 1975.

THOMPSON, J. L. The facets of the entrepreneur: identifying entrepreneurial potential. Management decision, Bradford, v. 42, n. 2, p. 243-258, fev. 2004. Disponível em: <http://www.emeraldinsight.com/Insight/viewContentItem.do?contentType $=$ Article\&hdAction=1nkpdf\&contentId=865481> Acesso em: 10 maio 2005.

TIMMONS, J. A.; SMOLLEN, L. E.; DINGEE, A. L. New venture creation: a guide to small business development. Illinois: Homewood, 1977.

WALTER, S. A.; WITTE, A.; DOMINGUES, M. J. C. S.; TONTINI, G. De Professor a Gestor: Uma Análise do Perfil dos Gestores dos Cursos de Administração das IES do Sistema Acafe. In: ENCONTRO NACIONAL DOS CURSOS DE GRADUAÇÃO EM ADMINISTRAÇÃO, 17, 2005, Belo Horizonte. Anais... Rio de Janeiro: ANGRAD, 2005.

WALTER, S. A.; ROCHA, D. T. da; DOMINGUES, M. J. C. de S.; TONTINI, G. De professor a gestor: uma análise dos cursos de administração das instituições de ensino superior da região Oeste do Paraná. Revista ANGRAD, Rio de Janeiro: ANGRAD, v. 8, n. 1, p. 53-72, jan./fev.mar. 2007. 